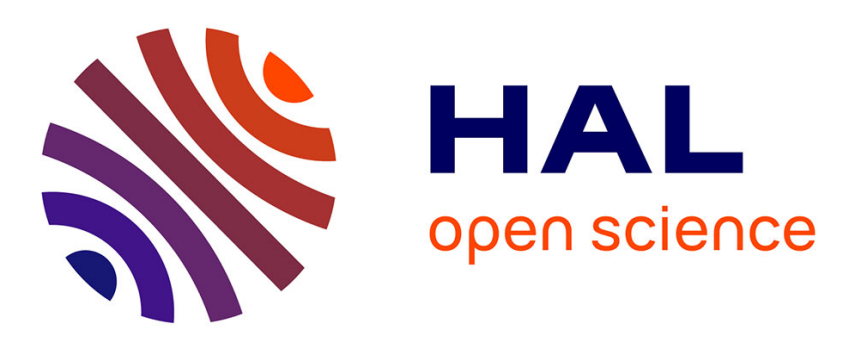

\title{
Experimental identification and associated model of the dissipation in the electric cables of a satellite structure
}

Christophe Cluzel, Philippe Rouch, Olivier Dorival, Stéphanie Behar

\section{To cite this version:}

Christophe Cluzel, Philippe Rouch, Olivier Dorival, Stéphanie Behar. Experimental identification and associated model of the dissipation in the electric cables of a satellite structure. Journal of Sound and Vibration, 2015, 357, pp.156-167. 10.1016/j.jsv.2015.07.033 . hal-01191660

\section{HAL Id: hal-01191660 \\ https://hal.science/hal-01191660}

Submitted on 2 Sep 2015

HAL is a multi-disciplinary open access archive for the deposit and dissemination of scientific research documents, whether they are published or not. The documents may come from teaching and research institutions in France or abroad, or from public or private research centers.
L'archive ouverte pluridisciplinaire HAL, est destinée au dépôt et à la diffusion de documents scientifiques de niveau recherche, publiés ou non, émanant des établissements d'enseignement et de recherche français ou étrangers, des laboratoires publics ou privés. 


\title{
Experimental identification and associated model of the dissipation in the electric cables of a satellite structure
}

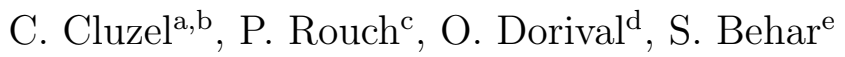 \\ ${ }^{a}$ LMT-Cachan/ENS-Cachan/CNRS/Université Paris Saclay, \\ 61 av. du Président Wilson, F-94230 Cachan, France \\ ${ }^{b} I U T-S G M$ d'Evry Val d'Essonne, rue du Père Jarlan, F-91025 Evry, France \\ ${ }^{c}$ Arts et Métiers ParisTech, 151 Boulevard de l'Hôpital, 75013 Paris France \\ ${ }^{d}$ Université de Toulouse; Institut Clément Ader (ICA); INSA, UPS, Mines Albi, ISAE, \\ 135 av. de Rangueil, 31077 Toulouse Cedex, France \\ ${ }^{e}$ Thales Alenia Space, 5 allée des Gabians, BP 99, 06156 Cannes La Bocca Cedex, France
}

\begin{abstract}
This paper presents a first experimental identification of the effects of electric cables on the damping of a satellite structure. The dissipation due to both the curvature of the cables and the slippage of the cables in their fasteners was taken into account based on classical plate kinematics. In order to validate a damping model for the cables, we developed tests to quantify the influence of the amplitude of the movement on the energy dissipated. Two cable sizes and three cable fastener heights were tested using a specific setup which made the curvature uniform along the whole length of the cables. The results show that while the dissipation is a function of the curvature the specific damping capacity is almost constant. However, the dissipation differs depending on the type of cable. Very small cables do not dissipate at all, but large cables can induce significant damping depending on the mode of vibration concerned.
\end{abstract}

Key words: Electric cable dissipation, sandwich panel, four-point bending test, vibration testing, damping model identification.

\section{Introduction}

The reliable prediction of the structural vibration behavior of satellites requires a knowledge of the sources of vibrations and overall damping level $[1,2,3]$ along with a suitable

URL: Olivier.Dorival@insa-toulouse.fr (O. Dorival)

Preprint submitted to Journal of Sound and Vibration

July 30, 2015 
dynamic model. This is a crucial step in the design process because, based on this prediction, the manufacturers provide the equipment suppliers with the acceleration levels that the various equipments must be capable of sustaining. A classical analysis of the dynamic behavior of a spacecraft, based on an assumed description of the modal damping, is used to qualify the stress level of each subcomponent. The modal damping factors are identified for the global structure using experimental modal analysis, which is an expensive and timeconsuming process. Conversely, in a predictive dynamic approach, the dissipation sources must be known and described quantitatively on a smaller scale.

The main sources of dissipation in a satellite are: the composite sandwich plates, the connections between plates, the cables and the components. A first study of sandwich panels was proposed in $[4,5,6]$. The dissipation was assumed to be proportional to the elastic strain energy of the elementary ply divided into longitudinal, transversal and shear parts for the skin. Each part was associated with a Specific Damping Capacity (SDC) which was assumed to be independent of the stress level being considered. A second study concerning the connection between structural panels was proposed in [7]. An experimental test showed that the SDC was not constant, but that it varied as a function of the vibration amplitude. Then Thales Alenia Space set out to study the other contributions to global damping. In [8], the authors presented experimental results concerning the effect of a series of complex fasteners in a sandwich panel on damping. The present work deals with the influence of electric cables on damping.

A cable is an arrangement of rigid and soft materials fixed on a panel. For very simple geometries, such as a damping layer inserted between a panel and a rigid layer, it is possible to express a relation between the viscoelastic properties of the damping layer and the macroscopic damping coefficient, as in $[9,10]$. In such an approach, the geometry on the microlevel is described using finite elements. However, the numerical modeling of cables is difficult because the geometries of the strands of cables and the specific fasteners are very complex. The usual way of taking into account the effect of cables on damping consists in carrying out experimental dynamic tests of the structure, including the cables and components. But this approach is not predictive and it provides no understanding of the origin 
of the dissipation. Another possible approach consists in performing a local analysis of the dynamic behavior of each component in order to achieve a better understanding and a quantification of the dissipative mechanisms. The long-term goal is to develop predictive tools for the simulation of dissipation, then to calculate the modal damping coefficients prior to carrying out tests on the complete satellite.

In this paper, the experimental procedure is based on a differential approach and on the use of a specific four-point bending setup to set and measure a bending displacement. During the launching stage, satellites (and, therefore, their connectors) are subjected to high loading levels. These loads are related to specific events such as engine ignition [11], engine shutdown [12], stage separation [13] and the deployment of panels [14]. In order to qualify a satellite, dedicated tests [15] are carried out prior to its launching. These tests are developed around specific frequency ranges and generate characteristic loads to be applied to the assemblies in order to simulate the in-flight vibrational environment. Such a simulation requires a very good understanding of the vibrational behavior of the satellite. Then, a modal damping equal to about $2 \%$ is assumed for some of the first modes of vibration which solicit the structure extensively. Previous studies of damping in honeycomb panels $[5,6,16]$ showed that even though panels and joints are subjected to high stresses, they cannot be considered to be the main sources of dissipation. Following the analysis of the panels and joints, a third step in the identification and modeling of the damping sources concerns the dissipative phenomena on the cable level. In order to simulate the values of the modal damping coefficients, one models the dissipation in each cable and its connections based on the movement of the cable. This movement, which is a function of the curvature of the plate alone, leads to the description of both the bending of the cables and their slippage in the fasteners taking into account their height relative to the mean plane of the plate. The dissipation in the cables is measured as a function of the amplitude of the movement for a given frequency. We developed a differential measurement procedure in order to separate the dissipation in the cables from the dissipation in the setup, and also to separate the dissipation due to the bending of the cables from the dissipation due to the fasteners. The determination of the SDC using the dissipation model requires two 
calculation steps. The first steps consists in calculating the eigenmodes. The second step consists, for each mode and for a given strain elastic energy of the structure, in integrating the movement of each cable to obtain the energy dissipated per cycle and per cable. The sum of the dissipated energies of all the cables divided by the elastic energy of the structure yields the contribution of the cables to the SDC. If the system is linear, which the results of our tests tend to indicate, the ratio of the dissipated energy to the elastic energy is constant and the calculation is straightforward. If this is not the case, the calculation must be repeated for several levels of elastic energy.

\section{Description of the cables being studied}

In a satellite, the electric cables may represent up to $30 \%$ of the overall mass. Therefore, their influence on damping can be significant. The cables are often laid out along the Cartesian directions and at different heights in order to allow the cables to cross one another, as shown in Fig. 1.

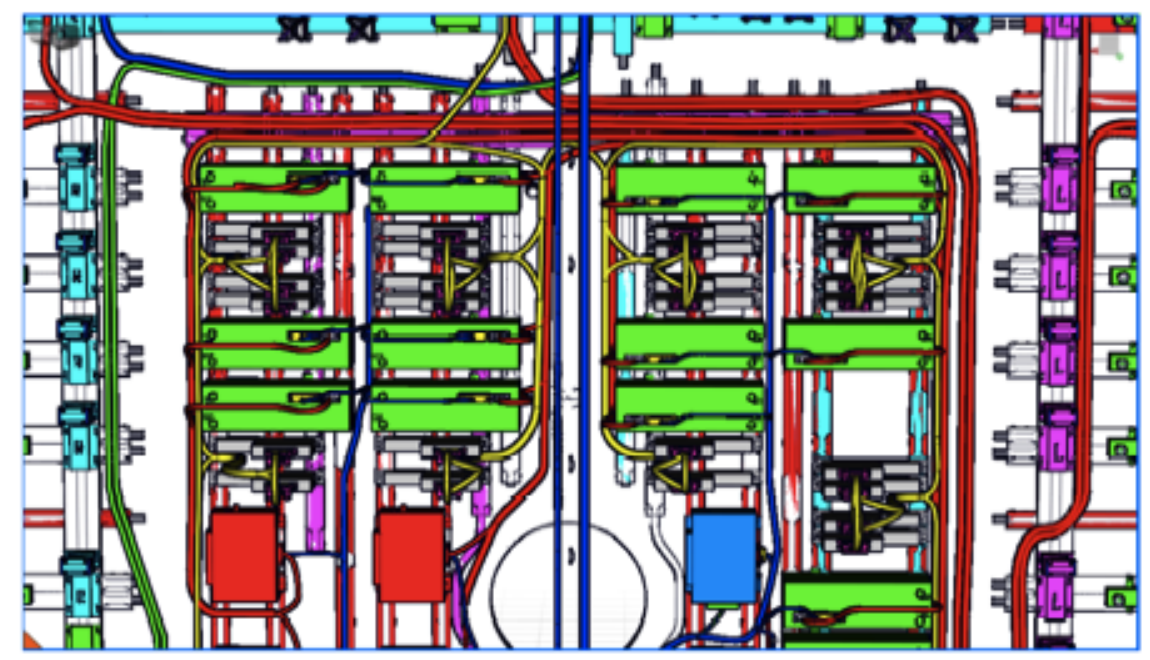

Figure 1: Example of a cable layout in a Thales satellite panel

In order to allow the cables to cross one another, it is necessary to use different support heights. The three support heights used in our experimental characterization are presented 
in Fig. 2. For the lowest support of height H1, the clamping piece is glued directly to the sandwich skin, whereas the others two use intermediate spacers of heights H2 and H3.

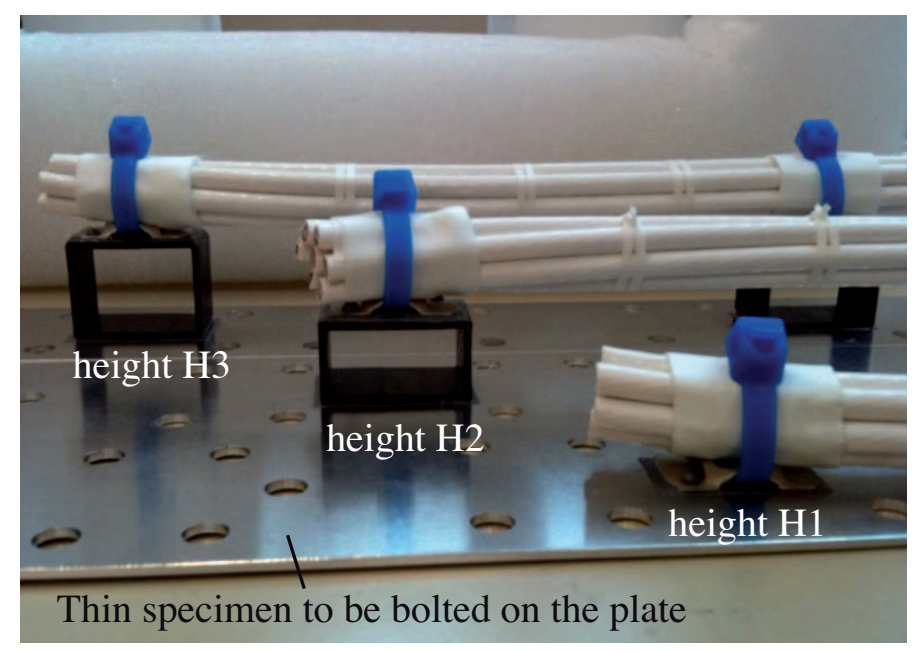

Figure 2: The three cable support heights tested

Another parameter concerns the size of the cable and the associated fastener. For this first experimental approach, we used the two cable sizes presented in Fig. 3: a white cable with $15 \mathrm{~mm}$ average strand diameter, and a red cable with $6 \mathrm{~mm}$ average strand diameter. The specimens were prepared by Thales Alenia Space with using the same process as for a real satellite.

\section{Definition of the cable dissipation parameters based on the kinematics of the panel}

In a modal damping analysis of a sandwich panel, each mode of vibration is associated with a specific SDC. In a local analysis, a modal deformation of the panel induces a specific cable deformation. Our main assumption is that for a given maximum panel deformation following a given mode the dissipation of a cable is proportional to the summation of a kinematic parameter which varies along the cable. Clearly, as illustrated by Fig. 4, for a given mode of the panel, each cable has its own amplitude of deformation and its contribution to the dissipation must be calculated as a function of the plate's modal deformation and its 


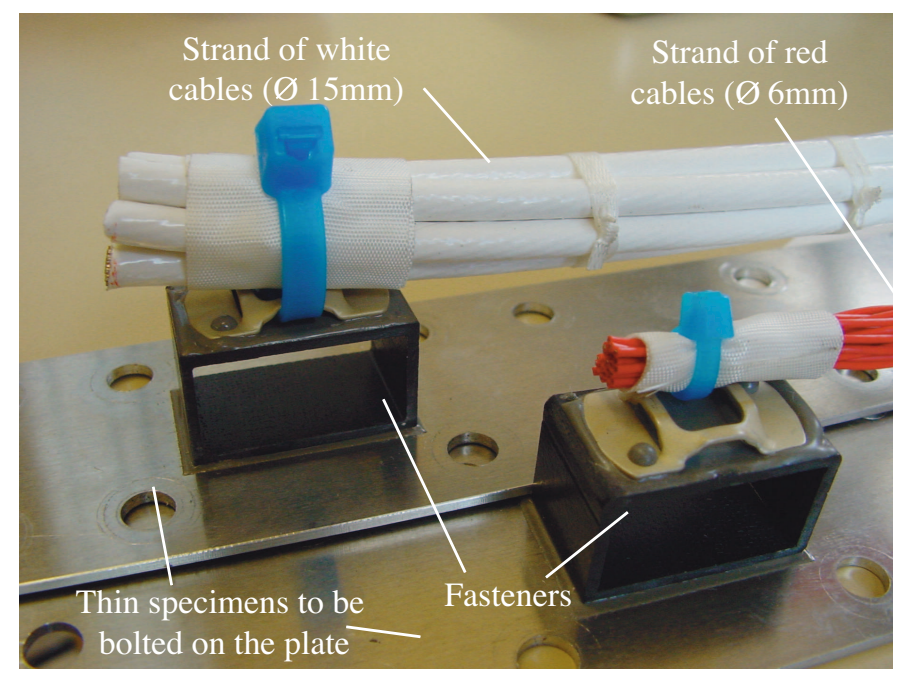

Figure 3: Detail of the fastening of two cable sizes

position on the plate.

In order to define the experimental parameters which are considered to control the cable's dissipation, we propose two mechanisms: the first mechanism is associated with the cable's curvature, which is assumed to be identical to the panel's curvature in the same direction, and results in a driving parameter denoted $\varphi$. The second mechanism, located in the cable fasteners, is attributed to microslippage between the cable and its support on the fastener's level and results in a driving parameter denoted $v$. Although the cables are fastened at discrete points (see Fig. 5), it is convenient to define a continuous parameter based on the assumption that the distance between fasteners is constant.

Consequently, between two fasteners $f_{i}$ and $f_{j}$, the curvature parameter $\phi_{i j}$ and the slippage parameter $V_{i j}$ which control the dissipation of a cable $L_{i j}$ for a given mode and a given magnitude are assumed to be defined by the following integrals along the cable:

$$
\begin{aligned}
\phi_{i j} & =\int_{L_{i j}}\left|\mathbf{S}^{t r} \chi \mathbf{S}\right|^{n_{1}} d s \\
V_{i j} & =\int_{L_{i j}} h\left|\mathbf{S}^{t r} \chi \mathbf{S}\right|^{n_{2}} d s
\end{aligned}
$$

where: 


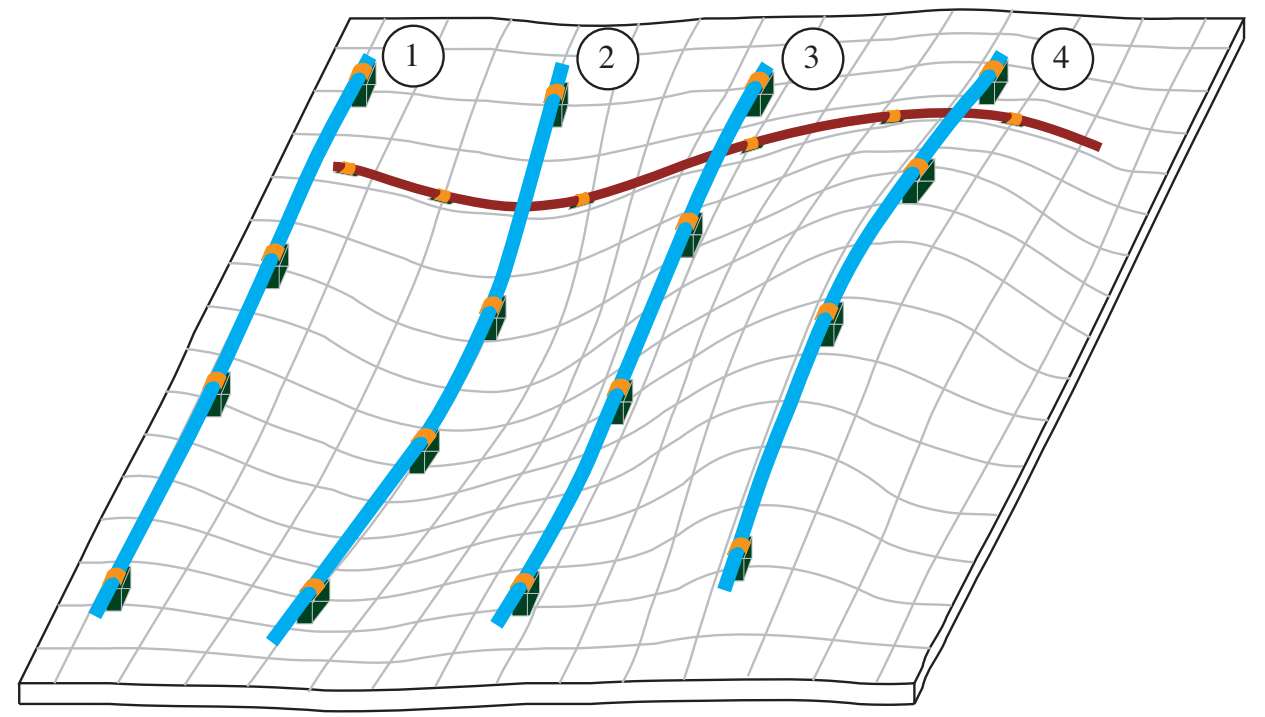

Figure 4: The cable displacements associated with a panel vibration mode

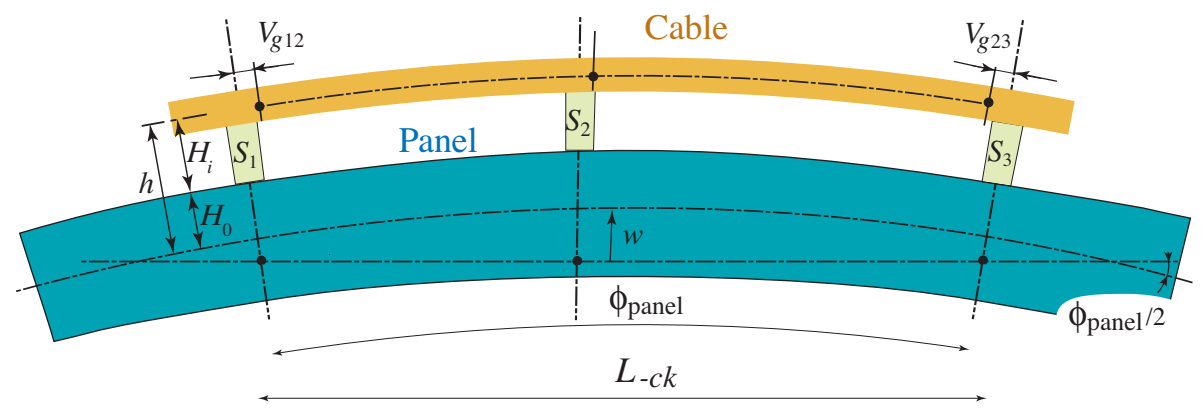

Figure 5: The kinematic parameters of a cable

- $\mathbf{S}$ is a normalized vector used as a projector in the direction of the cable,

$-\mathbf{S}^{t r}$ is the transpose of vector $\mathbf{S}$,

$-L_{i j}$ is the length of the cable between fasteners $i$ and $j$,

- $n_{1}, n_{2}$ are weighting parameters which affect the influence of the maximum curvature, but for easier identification, the choice is reduced to $n_{1}=n_{2}$

- $h$ is the height between the mean surface of the sandwich plate and the neutral axis of the cable, 
$-\chi$ is the plane curvature matrix based on Kirchhoff-Love's plate kinematics.

\section{The experimental setup}

The outcome of the experimental procedure must be the evolution of the dissipation as a function of the two variables for each cable considered. In order to simplify the identification of the function, the curvature of the cables can be chosen to be uniform. Thus, it can be obtained using a four-point bending test with the setup shown in Fig. 6. In this setup, each cable is fixed to its plate by four supports. Then, the constant curvature leads to a very simple expression of the driving forces normalized by the length of the cable between the two outermost supports:

$$
\begin{gathered}
\varphi=\frac{\phi_{14}}{L_{14}}=\left|\chi_{x x}\right|^{n_{1}} \\
v=\frac{V_{14}}{L_{14}}=h\left|\chi_{x x}\right|^{n_{2}}
\end{gathered}
$$

where $\chi_{x x}$ is the maximum curvature for each cycle and the length between the first and fourth supports is $L_{14}=669 \mathrm{~mm}$.

In order to minimize the dissipation by the setup itself, all the mechanical pivots were provided by the same flexible metallic connectors already used in [7] and [17]. Six identical specimens were fixed on an aluminum plate to ensure significant dissipation. Four strain gages were glued to the plate and connected as a full Wheatstone bridge to measure the curvature during the vibration response. The test consisted in free vibrations with an initial condition in the form of a pure displacement obtained using a $5 \mathrm{KN}$ electromagnetic holder in the center of the upper plate. The natural frequency of the setup was $16 \mathrm{~Hz}$, which corresponds to the low-frequency analysis requirement for the satellite. This frequency could be changed by modifying the stiffness of the middle plate and the mass of the setup structure, which can be made of steel or aluminum.

The supports glued to the aluminum plate and the cable clamps on the supports were provided by Thales Alenia Space. In order for us to be able to change the types of cables, 


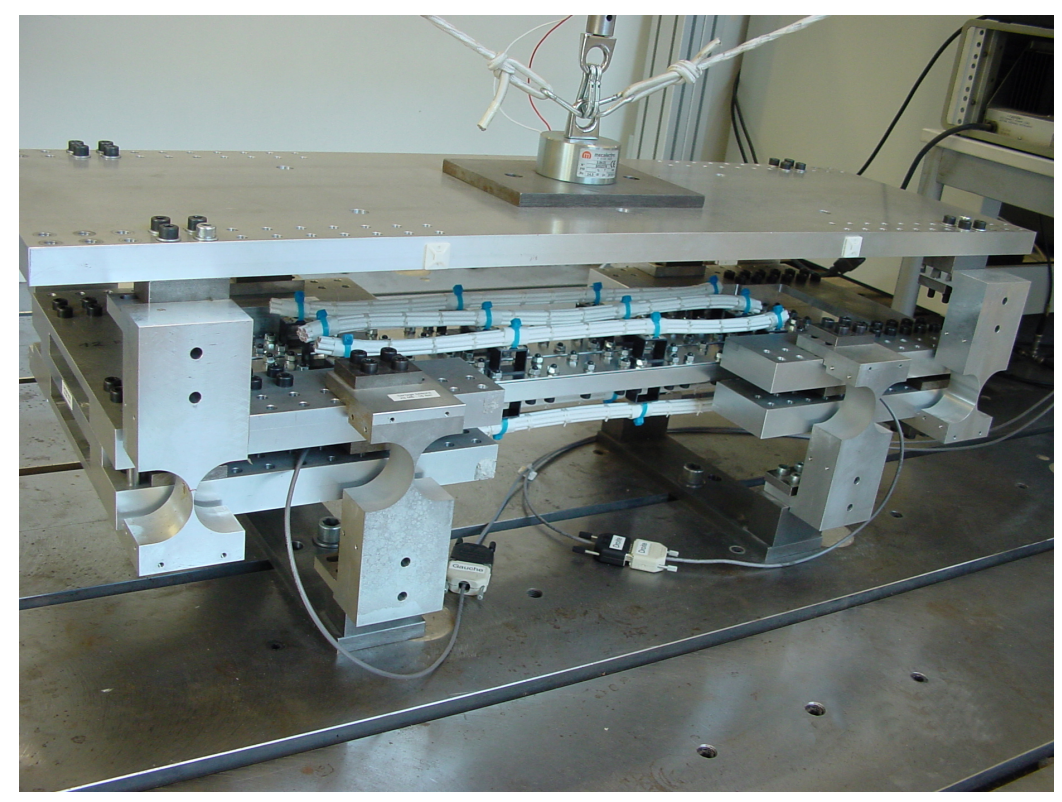

Figure 6: The four-point-bending experimental setup with six white cable specimens $(\phi 15 \mathrm{~mm})$

the number of cables or the heights of the supports, the cables were fixed on a thin plate which was bolted to the setup. Three heights were tested for both red and white cables, leading to 18 specimens for each type of cable as shown in Fig. 7.

Each specimen was attached to the aluminum plate of the setup using 50 nuts bolted with 50 calibrated washers between the setup and the specimen. The tightening of the bolts was controlled by a torque wrench in order to ensure a constant effect of this fastening on the dissipation. The low dissipation levels to be measured required that the damping of the setup be minimized and that a differential procedure be used for the identification. Then, the dissipation of the cables was measured by comparison between the dissipation of the setup with the cable specimens and the dissipation of a reference specimen, designated as RSUS (Reference SetUp and Specimen), which consisted of fastened plates without cables, as shown in Fig. 8. 


\section{Measurement of the SDC}

The first tests were performed in the reference configuration, i.e. the setup with six bolted plates and no cables. The global free vibration temporal response in the reference configuration is shown in Fig. 9. Using three initial loading levels, we found that for a given level of deformation the logarithmic decay was the same. The acquired signals were the output signals of the strain gage conditioner. Using four strain gages welded in a full bridge configuration, the measured voltage, after calibration, was converted directly into a curvature.

The main result of the experiment was the logarithmic decay. An automatic analysis of the damping was carried out and the logarithmic decay for a given curvature $\chi_{p+n / 2}$ and $n$ half-periods was obtained as:

$$
\delta(\chi)=\frac{1}{n}\left[\log \left(\left|\chi_{p+n}\right|\right)-\log \left(\left|\chi_{p}\right|\right)\right]
$$

This procedure enabled us to measure the variation of the SDC as a function of the curvature. In order to obtain a good estimate of the logarithmic decay using only five halfperiods $(n=5)$ as in Fig. 10, it was necessary to calibrate the zero value using the average signal before the identification.

Then the SDC was obtained as:

$$
\psi(\chi)=4 \delta(\chi)
$$

Figures 11 and 12 show the SDC as a function of the curvature for the various configurations tested.

One can observe that the SDC increases with the curvature. The influence of the cable is significant only for the white cables. The curves of Fig. 12 for the red cables and the reference specimen are almost identical. Therefore, from here on, we will focus on the white cables alone in order to identify and model the bending and slippage mechanisms. 


\section{Identification of the dissipation model}

In the previous section, the SDC values were extracted from the raw experimental results for various experimental configurations introduced in Section 2. In the following, those measurements are used to identify the dissipated energy of cables as a function of the bending of the plate and the slipping of cables into the fasteners, based on the modeling of the dissipation mechanisms detailed in Section 3. For a good identification procedure, the differential identification of dissipations is used to remove the dissipation of the setup.

\subsection{Derivation of the dissipated energy per cable}

The differential measurements of the effects of the cables must be defined in terms of energy. The total dissipated energy for each cycle as a function of the SDC and the elastic strain energy is given by:

$$
E_{\text {Total dissip./cycle }}=\psi_{\{\text {specimen }+ \text { cable }+ \text { setup }\}} E_{\text {Elastic strain energy } / \text { cycle }}
$$

The classical definition of the elastic strain energy based on Fig. 13 is:

$$
E_{\text {Elastic strain energy/cycle }}=\frac{1}{2} \chi M=\frac{1}{2} k \chi^{2}
$$

In order to calculate the product of the two functions in Eq. (7) while limiting the influence of the noise due to the small number of cycles, we carried out a polynomial fit of the SDC curves.

The stiffness $k$ was calibrated before each test using a static loading case with a known mass, even though its variation with the number of cables in the specimens was negligible.

In this case, the dissipation consisted of two parts, one related to the reference setup and the specimen, and the other related to the cables:

$$
E_{\text {Total dissipation } / \text { cycle }}=E_{\text {cable dissip./cycle }}+E_{\text {setup+reference dissip./cycle }}
$$

The evolution of the dissipation was obtained using the SDC measurements of Figs. 11 and 12 multiplied by the elastic energy. Fig. 14 shows that the influence of the cables on 
the stiffness is very limited.

As shown in Fig. 15, the dissipated energy of the setup with various specimens is influenced by both the number of cables and the height of the supports.

The advantage of an energy analysis is that each mechanism is associated with a dissipated energy. Thus, the differential identification procedure can be used to separate the energy dissipated in the cables from that dissipated in the fasteners and to eliminate the energy dissipated in the setup and in the specimen clamping devices. Based on the results of Fig. 16, this approach leads to useful conclusions in terms of the dissipation for a length $L_{14}$ of the cables during one cycle as a function of the maximum curvature during the cycle. In the various test configurations, 2, 4 or 6 cables were tested simultaneously. A first validation of the approach was obtained by calculating the dissipation for one cable from the three tests. Fig. 16 shows a uniform response from the three test configurations. The evolution of the dissipation was fitted as a function of $\left|\chi_{x x}\right|^{n_{1,2}}$ and the identification led to a good value $n_{1}=n_{2}=2$.

Fig. 17 shows that modeling the dissipation as a linear function of the number of cables leads to an accurate match with the discrete experimental results for 2, 4 and 6 cables and two heights.

\subsection{Identification of the bending and slipping mechanisms}

The model assumes that the damping in the cables involves two mechanisms. The first mechanism is associated with the bending of the cables and the second mechanism consists in the slippage of the cables in their fixations. This slippage is a linear function of the height between the average plane of the plate and the neutral axis of each cable. A plot of the energy dissipated in one cable as a function of the height for the various tests is shown in Fig. 18.

The evolution was modeled as an affine function of the height $h$ introduced into the model through the definition of $v$ in Eq. (4). Coefficients $k_{\varphi}=25,6 \mathrm{~J} . \mathrm{m}$ and $k_{v}=8450 \mathrm{~J} . \mathrm{m}^{-1}$ were identified by fitting a linear function. One should note that the values were identified for a curvature equal to $0.04 \mathrm{~m}^{-1}$. Then, the dissipation of one cable during one cycle, normalized 
by the length between four fasteners of the specimen $\left(3 L_{i j}\right)$, was defined using:

$$
\frac{E_{\text {Dissip. } / \text { cycle } / \text { cable }}}{3 L_{i j}}=k_{\varphi} \varphi+k_{v} v=k_{\varphi} \varphi+k_{v} h\left|\chi_{x x}\right|^{2}
$$

\subsection{Validation for other values of the curvature}

Next, the dissipation associated with the bending of the cables shown in Fig. 18 was calculated from the experimental data at each bending level. The dissipation associated with slippage of the cables was calculated, by difference with the total dissipation due to the cable, as a function of the square of the bending curvature. This decomposition of the dissipation of the cable is shown in Fig. 19 based on the average values of all the experimental curves and on the model with the constants of Eq. (10) identified previously.

\section{Discussion}

The analysis of the damping associated with the cables was carried out using a dissipated energy approach, which enables one to distinguish among the contributions of each mechanism and the dissipations associated with the setup, the bolted joint and the cables. The use of the model as a predictive tool involves two stages: first the simulation of all the dissipation phenomena, then the construction of the SDC.

\subsection{Simulation of the dissipation phenomena}

For a given mode, the kinematics is known and the driving parameters can be calculated as functions of the strain. Regarding the effects of the cables, the dissipation is modeled as a function of the bending curvature using the following equation:

$$
E_{\text {Dissip. } / \text { cycle }}=\sum_{i=1}^{n_{b}}\left[\sum_{j=1}^{n_{i}}\left(\left(k_{\varphi} \phi_{i j}+k_{v} V_{i j}\right)\right)\right]
$$

where

$-n_{b}$ is the number of cables,

$-n_{i}$ is the number of segments between two fasteners of Cable $i$. 
For the specimens which were tested in the setup, in which all the cables and all the segments have the same curvature, Eq. (11) can be rewritten as:

$$
E_{\text {Dissip. } / \text { cycle }}=n_{b} n_{i} L_{i j}\left(\left(k_{\varphi}\left|\chi_{x x}\right|^{2}+k_{v} h\left|\chi_{x x}\right|^{2}\right)\right)
$$

where $L_{i j}$ is the constant length between two fasteners.

The curves given in Fig. 20 show, in the case of the setup with a single cable, the dissipation model associated with the cables as a function of the curvature at various heights, including the case of the direct bending of the cable about its own neutral axis. In this simulation, the dissipations associated with the mechanical joint between the setup and the specimen and with the setup itself were disregarded.

\subsection{Construction of the specific damping capacity}

In order to simulate the dynamic response of a structure numerically, a good approach consists in using a modal damping capacity. Here, the specific damping capacity is defined as the ratio of the dissipated energy to the elastic energy [18]. The fact that the identified values of $n_{1}$ in Eq. (1) and $n_{2}$ in Eq. (2) were very close to 2 led us to the conclusion that the dissipations associated with both the curvature parameter $\phi_{i j}$ and the slippage parameter $V_{i j}$ are nearly proportional to the elastic strain energy. Therefore, the SDC associated with the cables alone is almost constant and independent of the bending curvature. The resulting SDC value for the cables at height H3 (shown in blue in Fig. 21) was found to be equal to 5\%. The good agreement with the corresponding SDC values derived experimentally (in red) confirms that the recovery of the SDC was satisfactory. For comparison, the black line in Fig. 21 shows the experimental SDC of the setup with bolted plates and no cable (RSUS). As noted in [7], the SDC of a bolted system depends on the amplitude. In order to obtain the actual SDC, one must take into account the dissipation of both the RSUS and the cables at height H3. Therefore, the final SDC is not simply the sum of the simulated SDCs of the cables and the RSUS. Instead, one must calculate the corresponding dissipated energies based on the plate's curvature in the direction of the cable, then total the dissipated energies as defined in Eq. (11). In the case of a vibrating structure, the curvature and slippage parameters in 
the direction of the cable must be calculated using projector $\mathbf{S}$ as in Eq. (1) and Eq. (2). In order to obtain the SDC of the structure, the dissipation in the cables must be added to the dissipation in the plate $([14,3])$, then divided by the total elastic energy of the structure over one cycle.

\section{Conclusion}

In this paper, we presented the first contributing elements to the understanding and modeling of the dissipation mechanisms due to the presence of electric cables in a satellite structure. The experimental study is based on the activation of a bending mode of the cables using a dedicated setup. The dissipation is expressed as a function of the curvature. Thus, one can use the results to calculate a modal damping coefficient which depends on the position of the cables on the plate. The experimental approach uses a differential analysis to separate the dissipation sources, thereby isolating the sources associated with the cables. The modeling of the dissipation of the cables is carried out by considering two mechanisms, one associated with the curvature of the cables and the other associated with the fastening system. Based on Kirchhoff-Love's plate kinematics, two parameters driving the dissipation are defined: one parameter is associated with the average curvature and the other is associated with slippage of the cables in their fasteners. Specimens developed in order to allow these parameters to vary were tested. The dissipation for one cable was derived from experiments as a function of the curvature of the support plate. Both mechanisms were identified and found to have the same order of magnitude. Based on these test results, a methodology for the integration of the effects of cables into the predictive simulation of the damping of satellite structures was presented.

\section{Acknowledgment}

Authors wish to gratefully acknowledge support from Thales Alenia Space for this project. 


\section{References}

[1] D.R. Augenstein, J.S. Baras, S.M. Fisher, Parameter identification of large spacecraft systems based on frequency characteristics, Proceedings of the 31st IEEE Conference on Decision and Control, Vol. 185, Tucson, AZ, U.S.A., 1993, pp. 624-635. doi:10.1109/CDC.1992.371137

[2] A. M. Kabe, Design and Verification of Launch and Space Vehicle Structures, Proceedings of the 39th AIAA/ASME/ASCE/AHS/ASC Structures, Structural Dynamics, and Materials Conference AIAA-981718, Long Beach, CA, U.S.A., 1998, pp. 175-189.

[3] J. J. Wijker, Spacecraft Structures, Springer Berlin Heidelberg, 2008. doi:10.1007/978-3-540-75553-1

[4] R. D. Adams, M. R. Maheri, The dynamic shear properties of structural honeycomb materials. Composites Science and Technology 47 (1) (1993) 15-23. doi:10.1016/0266-3538(93)90091-T

[5] M. R. Maheri, R. D. Adams, Modal vibration damping of anisotropic FRP laminates using the Rayleigh-Ritz energy minimization scheme. Journal of Sound and Vibration 259 (1) (2003) 17-29. doi:10.1006/jsvi.2002.5151

[6] M. R. Maheri, R. D. Adams, J. Hugon, Vibration damping in sandwich panels. Journal of Materials Science 43 (2008) 6604-6618. doi:10.1007/s10853-008-2694-y

[7] P. Rouch, C. Cluzel, O. Guezet, Meso-model and experimental identification of damping in joint of satellite sandwich panel, European Conference on Spacecraft Structures Toulouse, France, september 2009.

[8] S.C. Conlon, S.A. Hambric, Damping and induced damping of a lightweight sandwich panel with simple and complex attachments. Journal of Sound and Vibration 322 (4-5) (2009) 901-925. doi:10.1016/j.jsv.2008.12.006

[9] R.F. Kristensen, K.L. Nielsen, L.P. Mikkelsen, Numerical studies of shear damped composite beams using a constrained damping layer. Composite Structures 83 (3) (2008) 304-311. doi:10.1016/j.compstruct.2007.04.025

[10] L.H. He, Y.L. Liu, Damping behavior of fibrous composites with viscous interface under longitudinal shear loads. Composites Science and Technology 65 (6) (2005) 855-860. doi:10.1016/j.compscitech.2004.09.003

[11] S.A. Lane, M. Johnson, C. Fuller, A. Charpentier, Active control of payload fairing noise. Journal of Sound and Vibration 290 (3-5) (2006) 794-819. doi:10.1016/j.jsv.2005.04.017

[12] M. Shinozuka, J.-N. Yang, Peak structural response to non-stationary random excitations. Journal of Sound and Vibration 16 (4) (1971) 505-517. 10.1016/0022-460X(71)90659-6

[13] D. Jeyakumar, B. Nageswara Rao, Dynamics of satellite separation system. Journal of Sound and Vibration (297) (1-2) (2006) 444-455. doi:10.1016/j.jsv.2006.03.035

[14] M.K. Kwak, S. Heo, H.-B. Kim, Dynamics of satellite with deployable rigid solar arrays. Multibody 
System Dynamics 20 (2008) 271-286. doi:10.1007/s11044-008-9119-1

[15] T.D. Schar, K.Y. Chang, Force limited vibration testing of the Cassini spacecraft and instruments, 17th Aerospace Testing Seminar, Manhattan Beach, CA, U.S.A., 1997.

[16] J. Vaswani, N.T. Asnani, B.C. Nakra, Vibration and damping analysis of doubly curved sandwich panels with viscoelastic core. Aeronautical Journal of the Royal Aeronautical Society 88 (879) (1984) 395-403.

[17] S. Le Loch, Modélisation et identification de l'amortissement dans les structures spatiales, PhD Thesis, ENS Cachan, 2003.

[18] A. Caignot, P. Ladevèze, D. Néron, S. Le Loch, V. Le Gallo, K.M. Ma, T. Romeuf, Prediction of damping in space launch vehicles using a virtual testing strategy, 6th International Symposium on Launcher Technologies, Munich, Austria, november 2005. 
Figure 7: Six specimens of red cables with three heights and four supports 


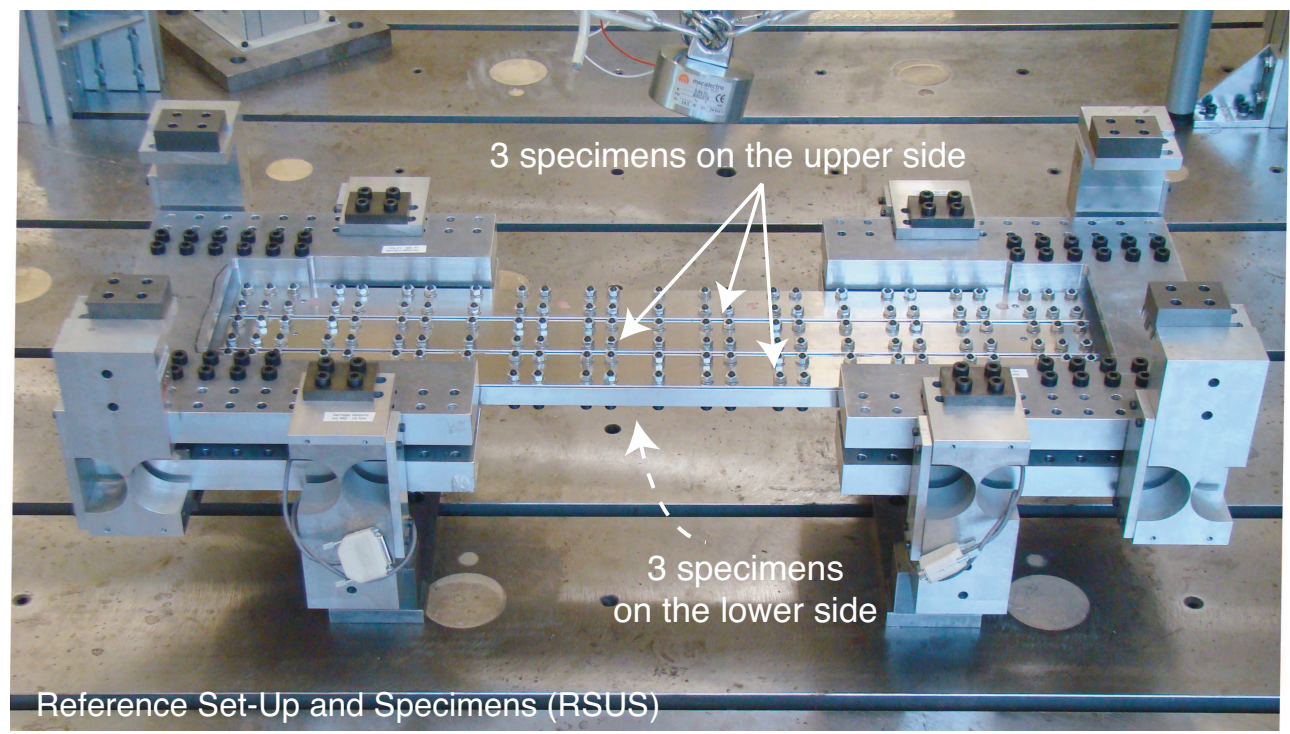

Figure 8: Detail of the setup with the six reference specimens

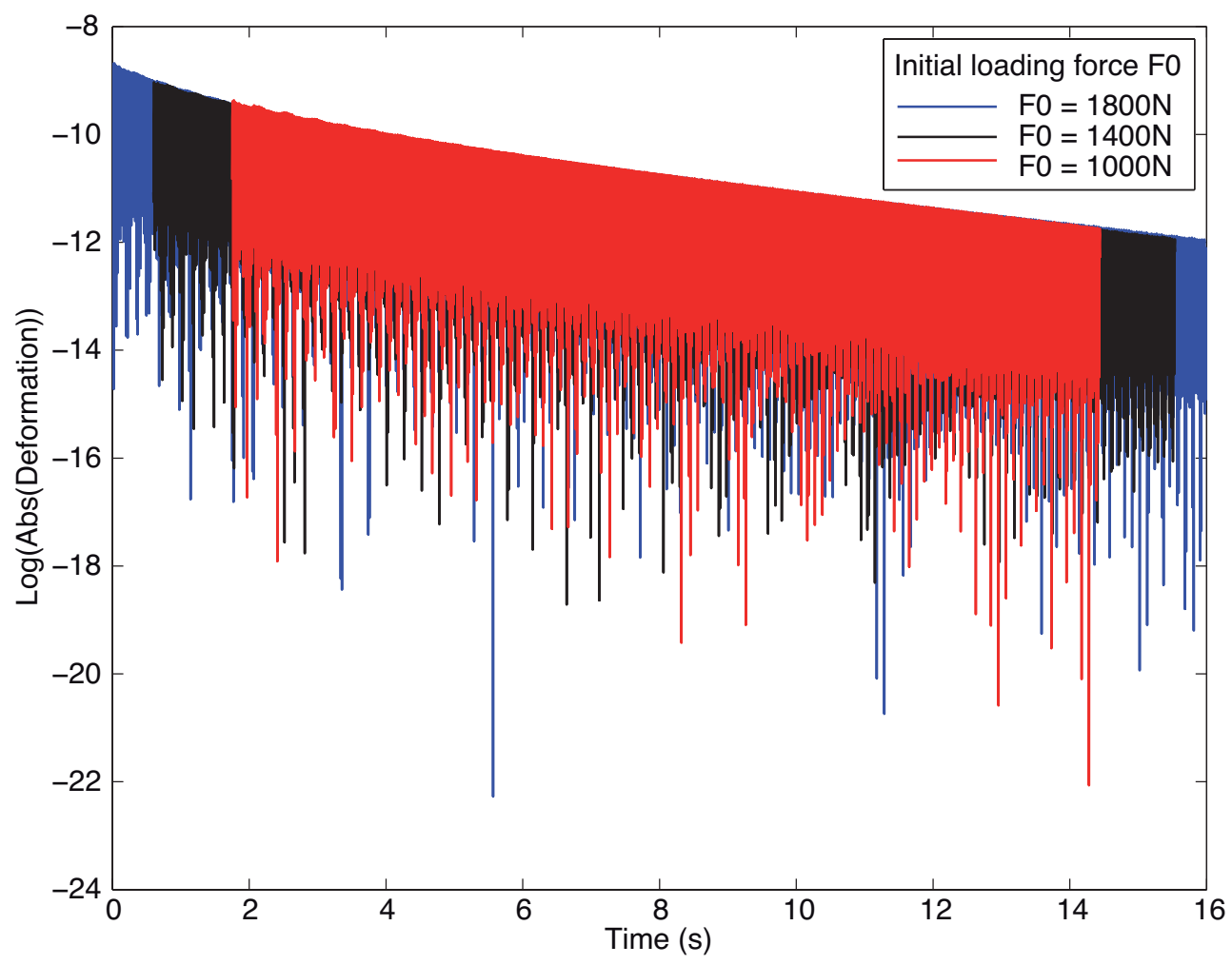

Figure 9: Log of the temporal free vibration response of the experimental setup with six specimens in the reference configuration and three initial loading levels 


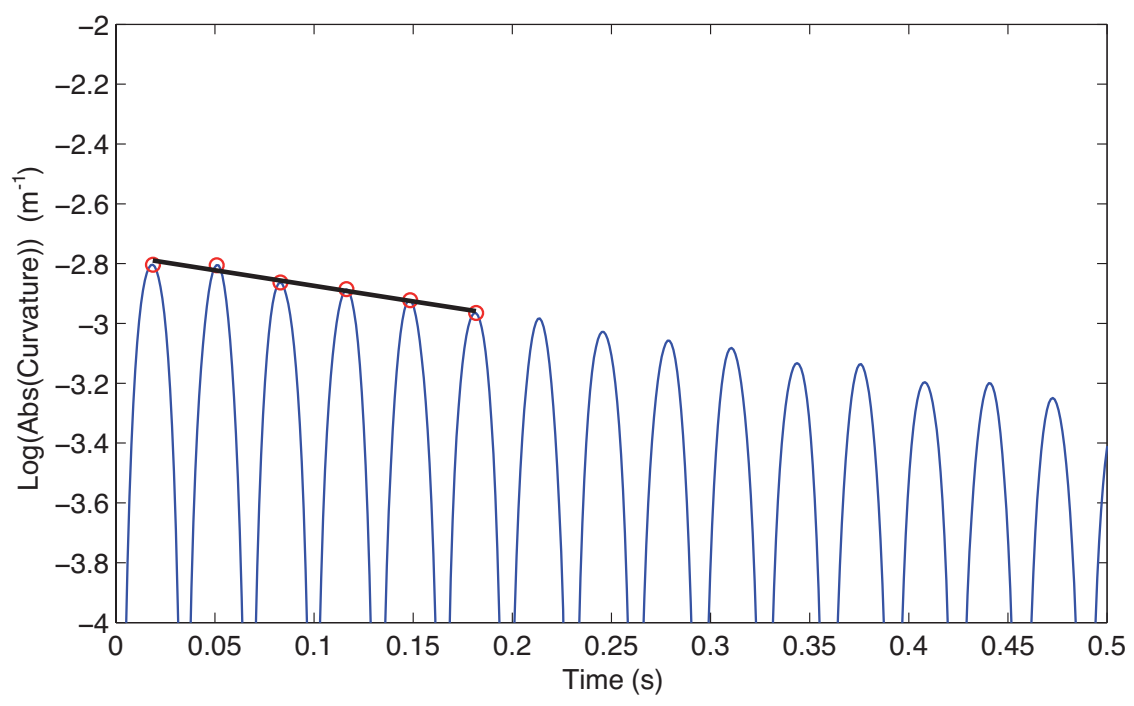

Figure 10: The temporal response of the strain gages: logarithmic decay based on five half-periods

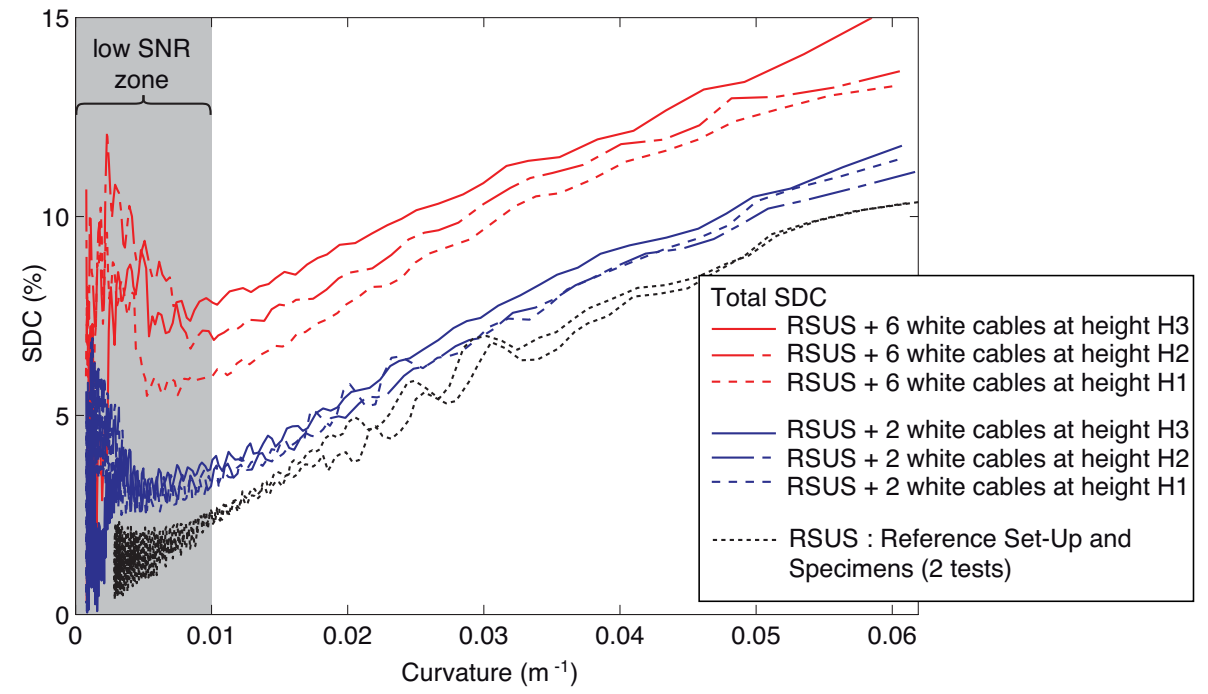

Figure 11: White cables: the SDC obtained experimentally as a function of the curvature for seven test configurations: 6 specimens with cables (RSUS +6 cables) at 3 heights (H1, H2, H3), 2 specimens with cables plus 4 reference specimens without cables (RSUS +2 cables) at 3 heights and six reference specimens without cable (RSUS) 


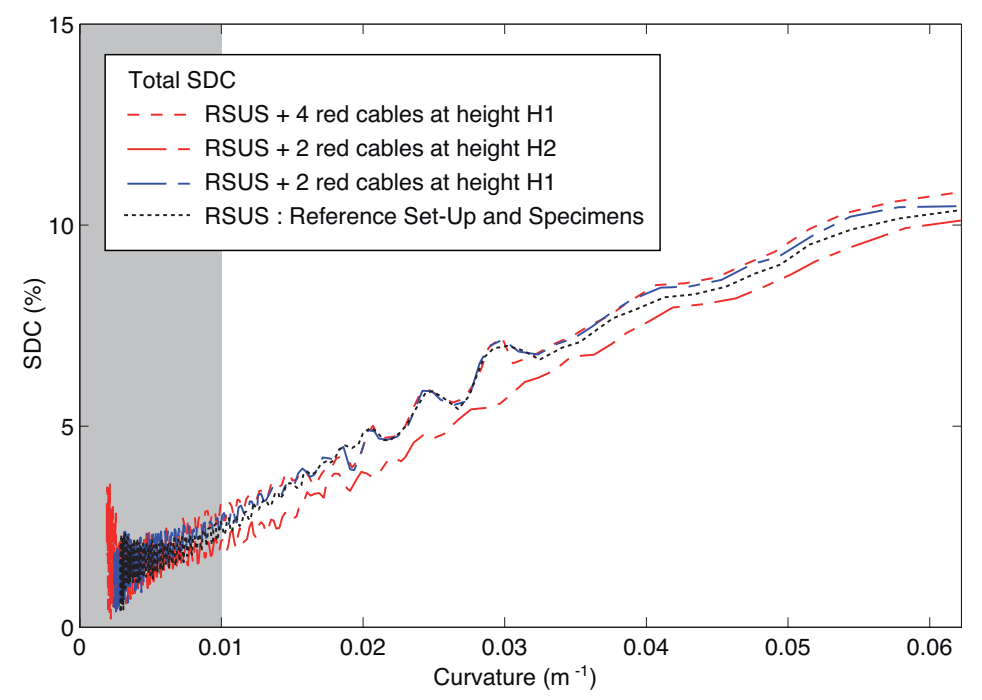

Figure 12: Red cables: the SDC as a function of the curvature for four test configurations: 4 specimens with cables plus 2 reference specimens without cables (RSUS +4 cables) at height H1, 2 specimens with cables plus 4 reference specimens without cables (RSUS +2 cables) at 2 heights (H2, H1) and six reference specimens without cable (RSUS)

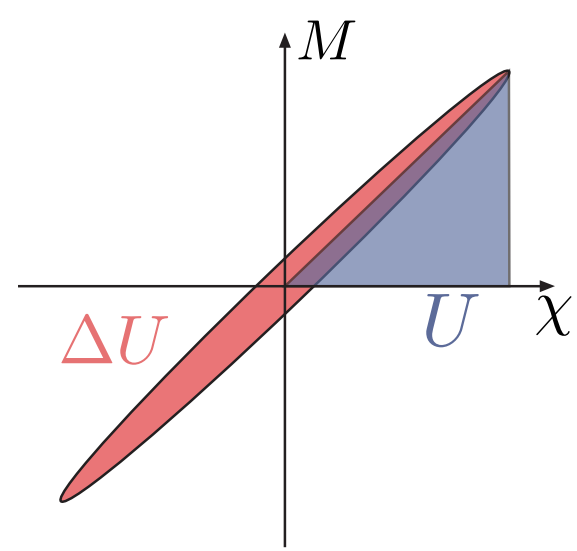

Figure 13: Definition of the elastic strain energy 


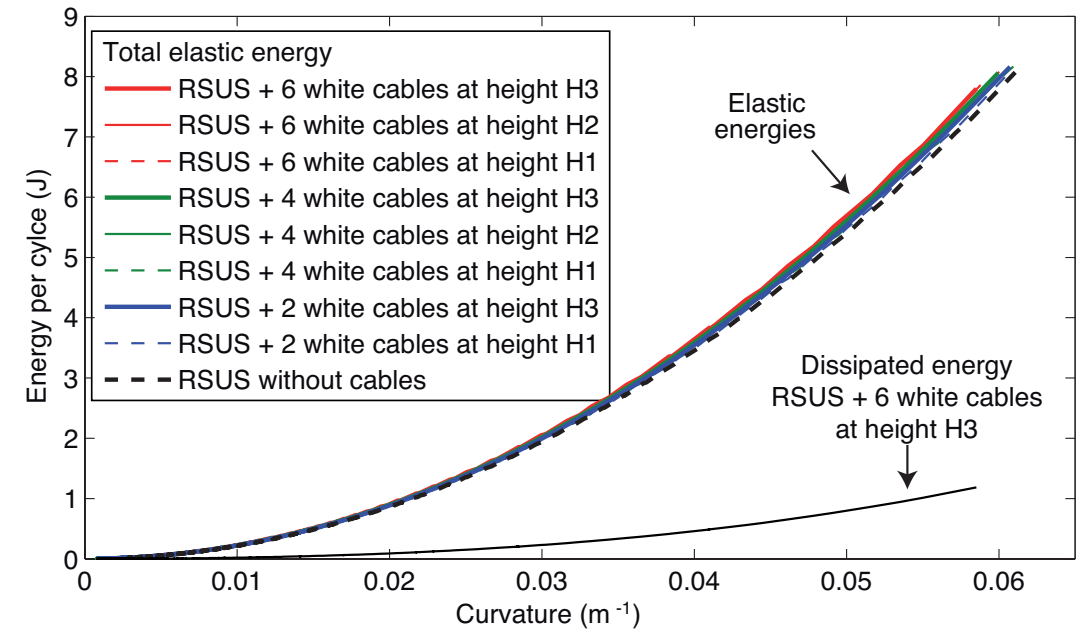

Figure 14: The elastic strain energy during one period in various configurations and the corresponding dissipation with six white cable specimens at height $\mathrm{H} 3$ as functions of the bending curvature

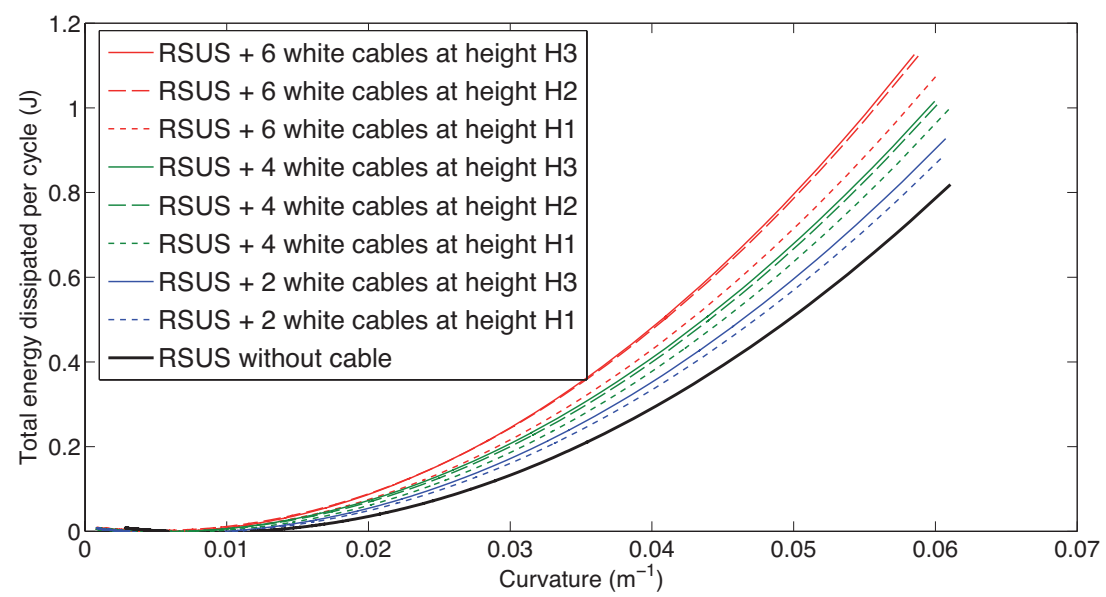

Figure 15: The influence of the height and the number of cables on the total dissipation during one period as a function of the bending curvature 


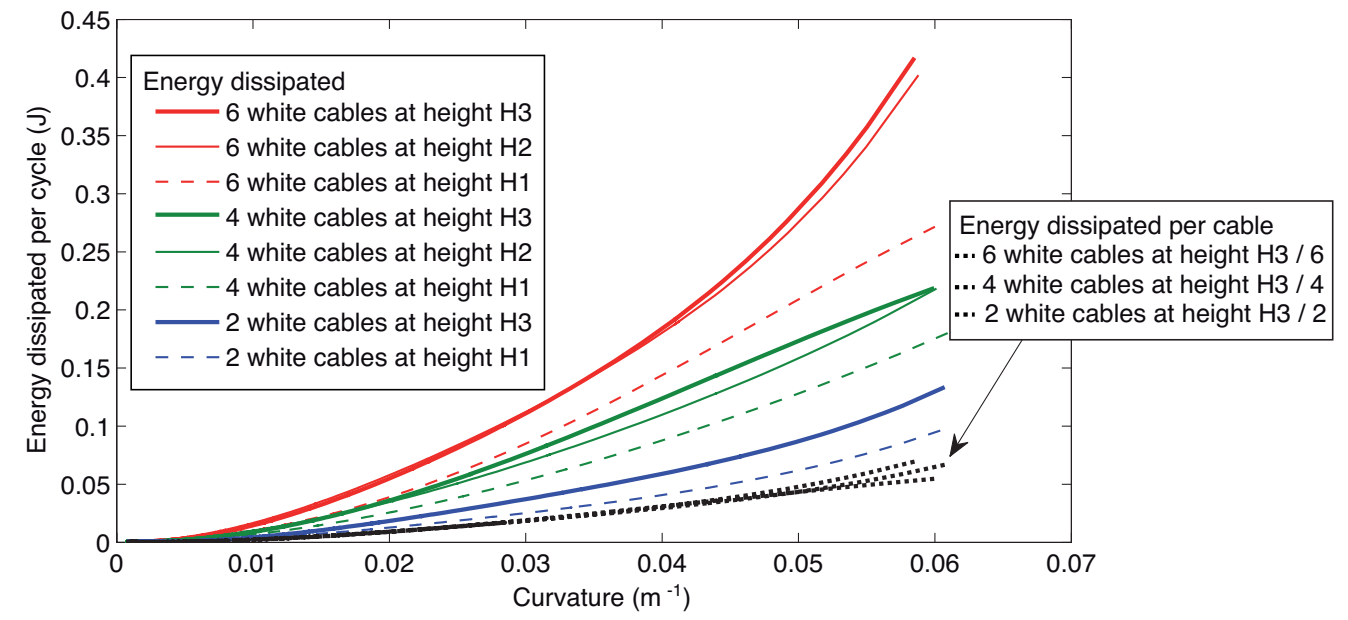

Figure 16: The dissipated energy for 2, 4 and 6 cables during one period, and the normalized energy for one cable as a function of the bending curvature

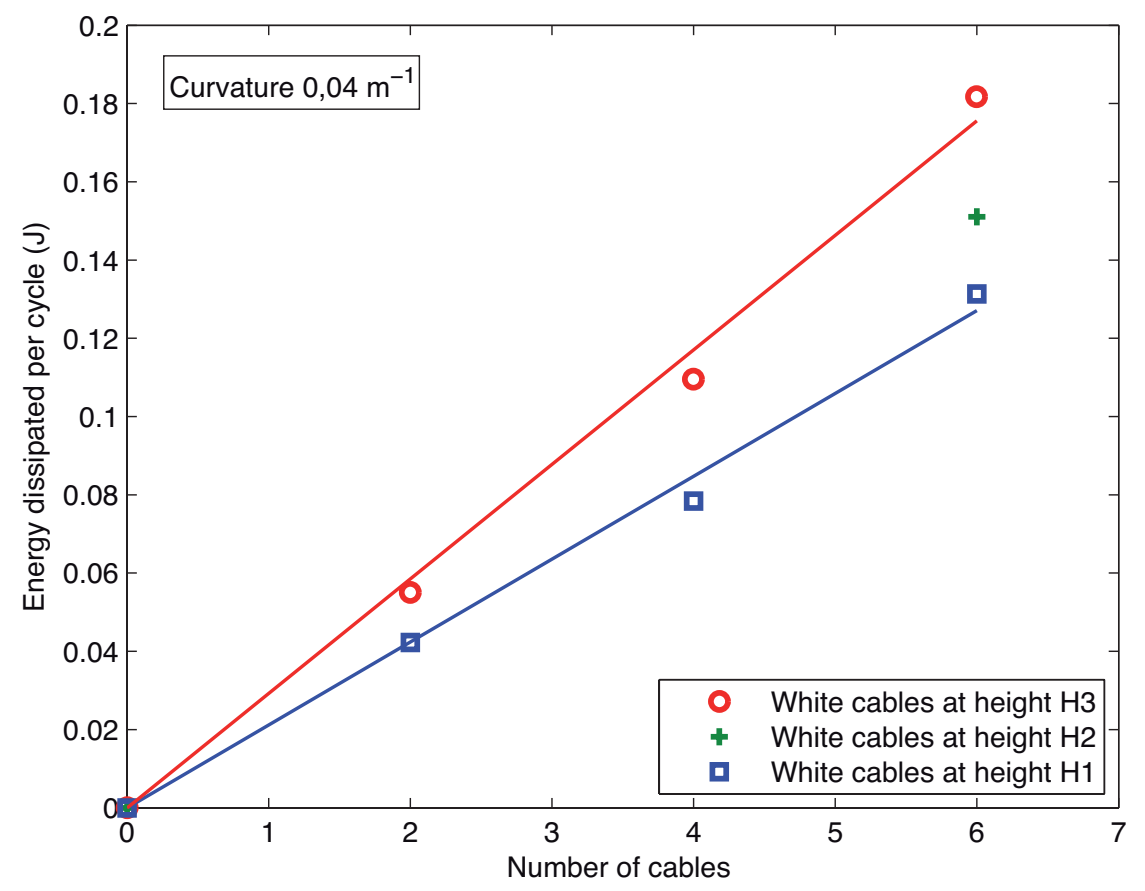

Figure 17: The dissipated energy during one period for a specific bending curvature as a function of the number of cables 


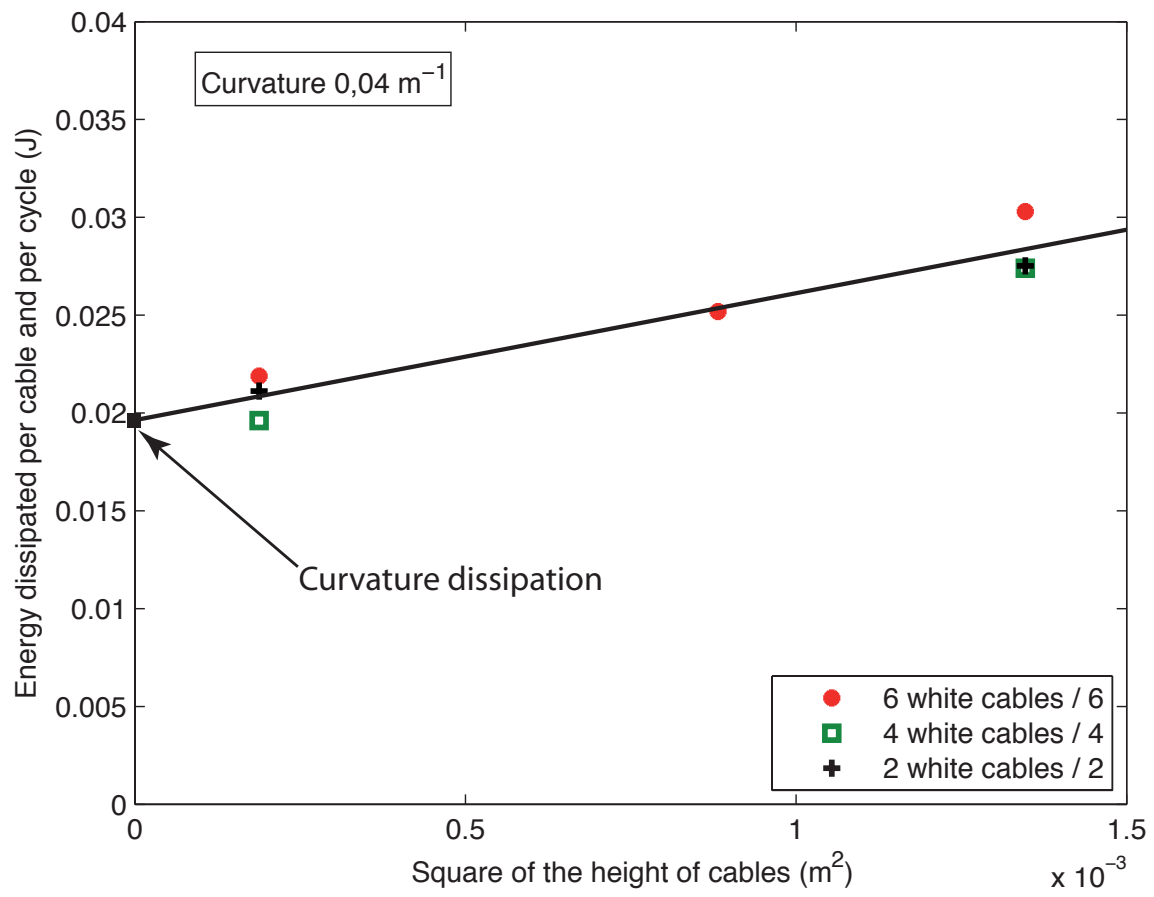

Figure 18: The dissipated energy in one cable during one period as a function of the height 


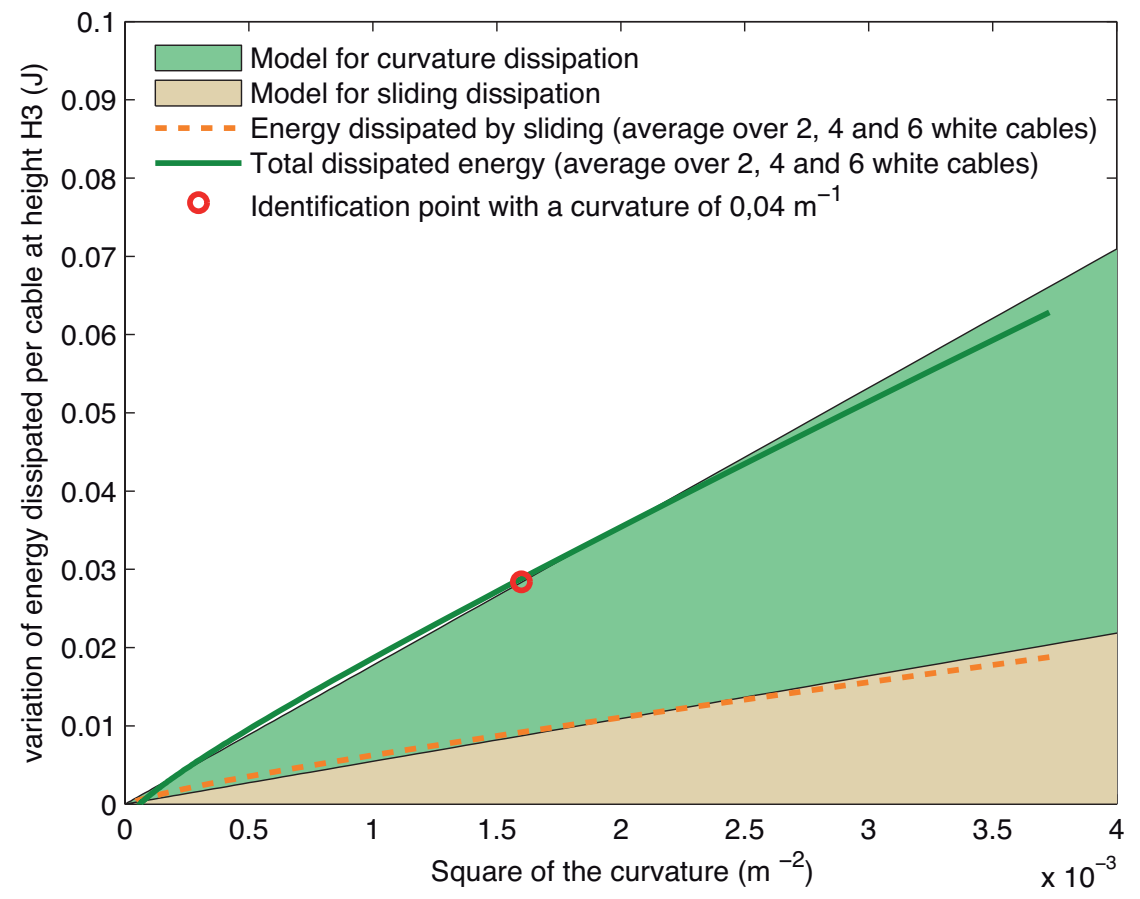

Figure 19: Decomposition of the dissipation of one cable during one period into bending dissipation and slippage dissipation 


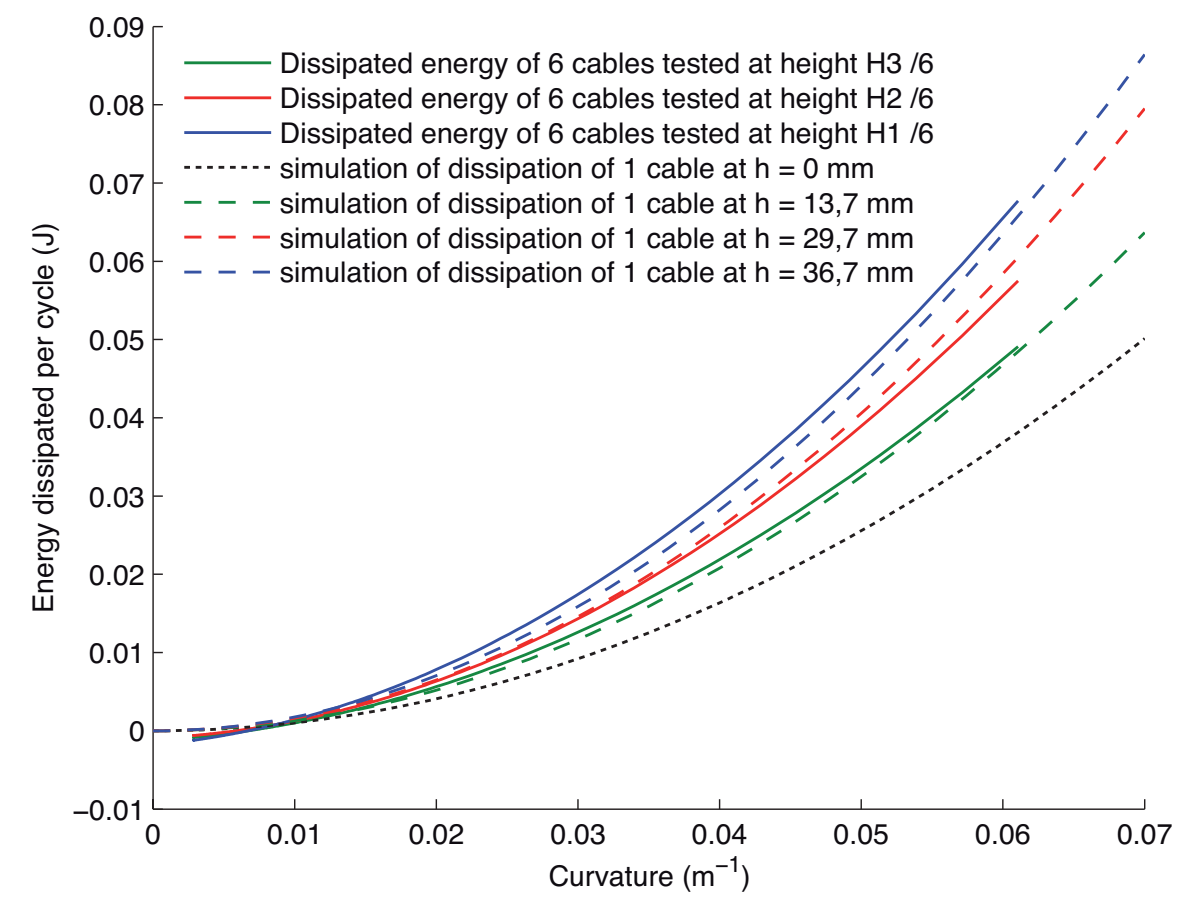

Figure 20: Comparison between the experimental and calculated dissipated energy in one cable during one period, at various heights, as functions of the bending curvature

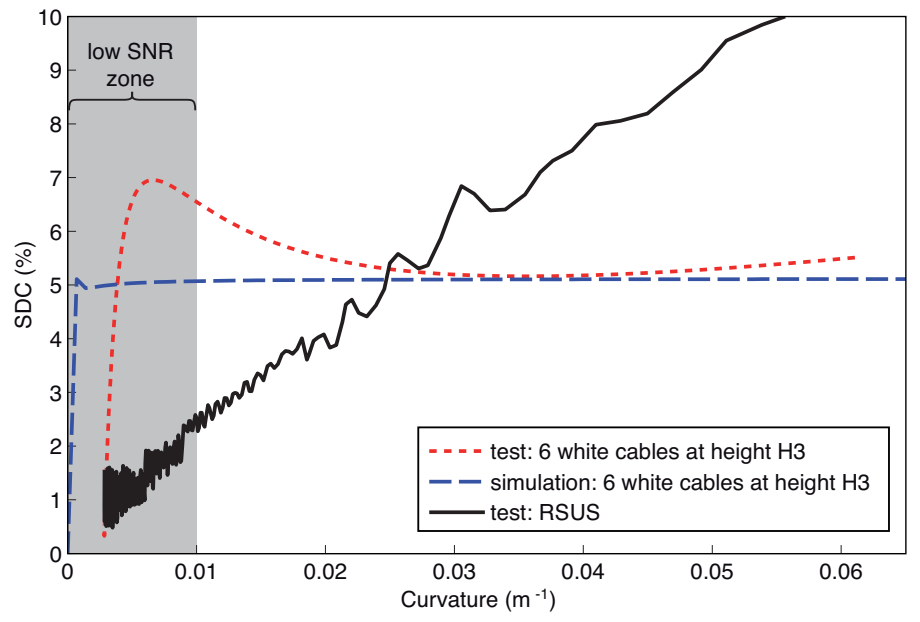

Figure 21: Comparison of the simulated SDC for the setup with six white cables and no other dissipation source and the setup dissipation with the screwed reference specimens 